\title{
Early Hyperglycemia in Pediatric Traumatic Brain Injury Predicts for Mortality, Prolonged Duration of Mechanical Ventilation, and Intensive Care Stay
}

\author{
Shu-Ling Chong, ${ }^{1,2}$ Sumitro Harjanto, ${ }^{3}$ Daniela Testoni, ${ }^{4} \mathrm{Zhi}$ Min Ng, \\ Chyi Yeu David Low, ${ }^{6}$ Khai Pin Lee, ${ }^{1,2}$ and Jan Hau Lee ${ }^{2,7}$ \\ ${ }^{1}$ Department of Emergency Medicine, KK Women's and Children's Hospital, 100 Bukit Timah Road, Singapore 229899 \\ ${ }^{2}$ SingHealth Duke-NUS Paediatrics Academic Clinical Programme, 100 Bukit Timah Road, Singapore 229899 \\ ${ }^{3}$ Duke-NUS Graduate Medical School, 8 College Road, Singapore 169857 \\ ${ }^{4}$ Division of Neonatal Medicine, Escola Paulista de Medicina-Universidade Federal de Sao Paulo, Rua Marselhesa 630, \\ Vila Clementino, 04020-060 São Paulo, SP, Brazil \\ ${ }^{5}$ Department of Paediatric Medicine, KK Women's and Children's Hospital, 100 Bukit Timah Road, Singapore 229899 \\ ${ }^{6}$ Department of Neurosurgery, KK Women's and Children's Hospital, 100 Bukit Timah Road, Singapore 229899 \\ ${ }^{7}$ Children's Intensive Care Unit, KK Women's and Children's Hospital, 100 Bukit Timah Road, Singapore 229899 \\ Correspondence should be addressed to Shu-Ling Chong; chong.shu-ling@kkh.com.sg
}

Received 25 November 2014; Revised 23 April 2015; Accepted 30 April 2015

Academic Editor: Constantinos Pantos

Copyright (C) 2015 Shu-Ling Chong et al. This is an open access article distributed under the Creative Commons Attribution License, which permits unrestricted use, distribution, and reproduction in any medium, provided the original work is properly cited.

\begin{abstract}
We aim to study the association between hyperglycemia and in-hospital outcomes among children with moderate and severe traumatic brain injury (TBI). This retrospective cohort study was conducted in a tertiary pediatric hospital between 2003 and 2013. All patients < 16 years old who presented to the Emergency Department within 24 hours of head injury with a Glasgow Coma Scale $(\mathrm{GCS}) \leq 13$ were included. Our outcomes of interest were death, 14 ventilation-free, 14 pediatric intensive care unit(PICU-) free, and 28 hospital-free days. Hyperglycemia was defined as glucose $>200 \mathrm{mg} / \mathrm{dL}$ (11.1 mmol/L). Among the 44 patients analyzed, the median age was 8.6 years (interquartile range (IQR) 5.0-11.0). Median GCS and pediatric trauma scores were 7 (IQR $4-10)$ and 4 (IQR 3-6), respectively. Initial hyperglycemia was associated with death (37\% in the hyperglycemia group versus $8 \%$ in the normoglycemia group, $p=0.019$ ), reduced median PICU-free days ( 6 days versus 11 days, $p=0.006$ ), and reduced median ventilation-free days ( 8 days versus 12 days, $p=0.008$ ). This association was however not significant in the stratified analysis of patients with GCS $\leq 8$. Conclusion. Our findings demonstrate that early hyperglycemia is associated with increased mortality, prolonged duration of mechanical ventilation, and PICU stay in children with TBI.
\end{abstract}

\section{Background}

Traumatic brain injury (TBI) remains a significant health burden worldwide [1,2]. First-line physicians are particularly interested in predictors for severe injury. This is especially relevant in pediatrics, due to the varied and nonspecific complaints among head-injured children. Age, Glasgow Coma Scale (GCS), accidental hypothermia, hyperglycemia, and coagulation disorders are reported to be independent prognostic factors for mortality [3].
Among adults with TBI, studies demonstrated an association between hyperglycemia and poor neurological outcomes [4-7]. Similarly, hyperglycemia prognosticated children with TBI [8-11]. Specifically, a recent paper demonstrated that severe hyperglycemia (>200 mg/dL $\{11.1 \mathrm{mmol} / \mathrm{L}\}$ ) was associated with poor Glasgow Outcome Scores when compared with mild blood glucose elevation $(110-160 \mathrm{mg} / \mathrm{dL}$ $\{6-9 \mathrm{mmol} / \mathrm{L}\})$ [12]. Furthermore, persistent hyperglycemia beyond the initial presentation was associated with poorer neurological outcomes [13] and death [14]. However, this 
association is not consistent; other investigators have demonstrated that hyperglycemia associated with pediatric closed head injury was transient and did not predict patient outcomes [15].

Previous studies have focused primarily on mortality as their outcome of interest. Furthermore, there are only limited published studies in this area in Asia [16]. To add to the evidence provided by previous investigators, we were specifically interested in examining the impact of hyperglycemia on inhospital outcome measures such as duration of mechanical ventilation, length of pediatric intensive care unit (PICU), and hospital stay in children with TBI. We performed a study to examine the association between hyperglycemia and clinical outcomes in children with moderate (GCS 9-13) and severe TBI (GCS $\leq 8)$. We hypothesized that hyperglycemia, in children with moderate to severe TBI, is associated with death, prolonged duration of mechanical ventilation, PICU, and hospital stay.

\section{Methods}

2.1. Study Design and Setting. We conducted a retrospective cohort study in KK Women's and Children's Hospital, Singapore. Our hospital is a large tertiary center that sees about 28,000 trauma patients at the emergency department (ED) annually. The majority of these comprise minor trauma. We traced all records coded under the International Classification of Diseases (ICD) diagnosis of head injury with a GCS of $\leq 13$. All patients $<16$ years of age who presented to the ED over the period from 2003 to 2013, with GCS $\leq 13$, were included. Patients were excluded if they were $\geq 16$ years, received prior treatment at another hospital and were transferred $>24$ hours after the head injury, were drowsy from other causes (apart from the head injury), or did not have any glucose levels documented in the ED or PICU. Children with moderate to severe TBI in our institution are routinely maintained with head up nursing (once the cervical spine is cleared), normocarbia, strict temperature control and we utilize hyperosmolar therapy when indicated. Morphine and midazolam are routinely used for analgesia and sedation, whereas paralysis is reserved for cases with high intracranial pressure (ICP). During the 10-year period, mannitol was replaced with $3 \%$ hypertonic saline as the choice hyperosmolar agent. Secondly, where cooling was previously attempted in the past, we now aim for normothermia for the past 23 years following current evidence $[17,18]$. Throughout the 10 -year period, second tier management included the use of thiopentone and, in some cases, decompressive craniectomy.

Our local institutional review board approved this study without the need for informed consent.

2.2. Variables. Demographic details of each patient were collected. We reviewed presenting glucose levels at the $\mathrm{ED}$, and subsequent peak values recorded in the PICU at 0-24 hours, 24-48 hours, and 48-72 hours. We defined hyperglycemia as glucose $>200 \mathrm{mg} / \mathrm{dL}$ (11.1 mmol/L) [13]. As part of a sensitivity analysis, we repeated our analysis using a different glucose threshold for hyperglycemia: $150 \mathrm{mg} / \mathrm{dL}$
(8.3 mmol/L) [13]. We also collected data on the mechanism of injury, presenting GCS, presence of polytrauma, as well as pediatric trauma scores (PTS). We divided presenting GCS into two groups: GCS $\leq 8$ and GCS $>8$. The PTS is a measure of injury severity, as measured by the weight of the child, the airway status, systolic blood pressure, level of consciousness, and the type and complexity of fractures or wounds present $[19,20]$.

2.3. Outcome Measures. Our primary outcome was hospital mortality. Secondary outcomes were duration of mechanical ventilation, PICU, and hospital length of stay (LOS). To account for death as a competing outcome, we summarized the requirement for mechanical ventilation as ventilator-free days with a maximum of 14 days. For LOS, we utilized PICUfree and hospital-free days with a maximum of 14 and 28 days, respectively.

2.4. Statistical Methods. Data were summarized and reported in the following way: Continuous variables were presented as medians (with interquartile ranges (IQR)), while binary or categorical data was presented as numbers and frequencies (\%). Univariate statistical tests for binary or categorical variables were conducted by chi-square test, while continuous variables were assessed by the Mann-Whitney test. We performed a separate stratified analysis of children with GCS $\leq 8$. Statistical significance was taken as $p$ values $<0.05$ for all tests. Statistical analysis was performed using Stata 12.1 (College Station, TX).

\section{Results}

Out of a total of 59 patients who matched the inclusion criteria, three were excluded because of prior care in other institutions and had a delayed transfer of $>24$ hours to our hospital. Five were found to have drowsiness attributed to causes other than the head injury and seven patients had incomplete data; they did not have glucose measurements in the ED or during the PICU stay (Figure 1). Of the 44 patients with complete data, the median age was 8.6 years (IQR 5.0-11.0), with a median GCS of 7 (IQR 4-10) and a median PTS of 4 (IQR 3-6) (Table 1). Three patients who were transferred from other local institutions had a median delay of 5 hours between the time of injury and time of arrival in our center. The most common mechanism of injury was by motor vehicle accidents (22 patients, 50.0\%). 21 (47.7\%) patients had polytrauma. The overall mortality was $9 / 44$ (20.5\%). There were 16 patients $(36.4 \%)$ who sustained skull and base of skull fractures, $36(81.8 \%)$ with focal intracranial bleeds (not exclusive: SDH (16, 44.4\%), EDH (13, 36.1\%), SAH (8, 22.2\%), and intraparenchymal bleed (8, 22.2\%). 20 (45.5\%) patients had cerebral edema and 7 (15.9\%) had diffuse axonal injury.

Thirty-one $(70.5 \%)$ patients underwent neurosurgical interventions. Of these, the majority (30 patients, 96.8\%) underwent insertion of extraventricular catheter for ICP monitoring, while 15 patients (48.4\%) underwent evacuation of intracranial clots. Among the 44 patients, we only had documented ICP and cerebral perfusion pressure (CPP) 


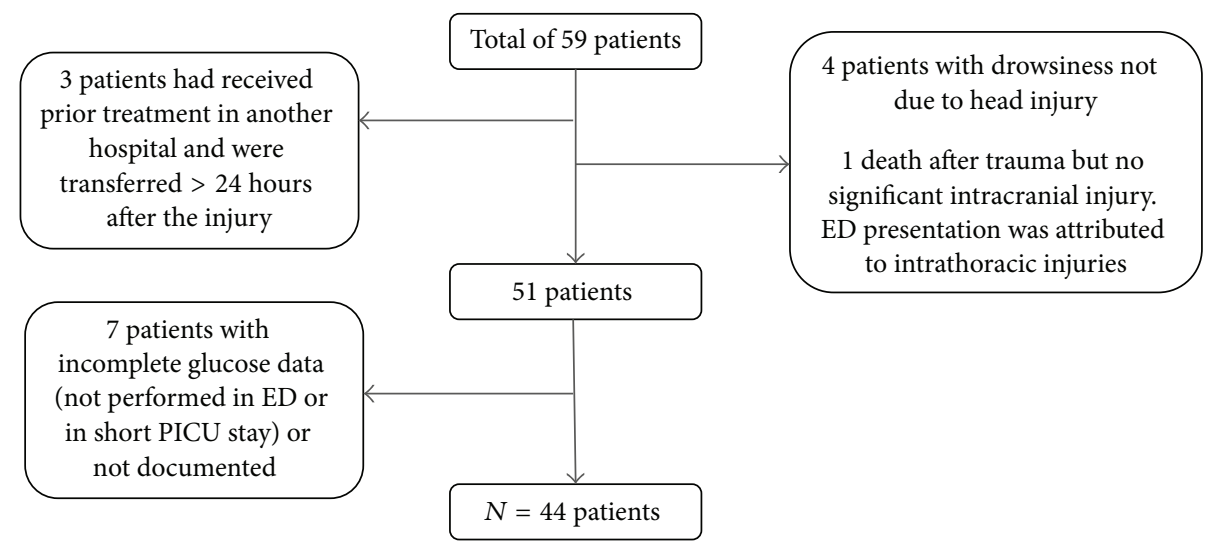

ED: emergency department; PICU: pediatric intensive care unit

FIGURE 1: Flow chart of cohort of children with moderate to severe traumatic brain injury.

TABLE 1: Clinical demographics and mechanism of injury for both survivors and nonsurvivors with moderate and severe traumatic brain injury.

\begin{tabular}{|c|c|c|c|c|}
\hline & $\begin{array}{c}\text { All } \\
(n=44)\end{array}$ & $\begin{array}{l}\text { Survivors } \\
(n=35)\end{array}$ & $\begin{array}{l}\text { Nonsurvivors } \\
\quad(n=9)\end{array}$ & $p$ value \\
\hline Age (years), median $\left(\mathrm{IQR}^{\mathrm{a}}\right)$ & $8.6(5.0-11.0)$ & $9.2(6.4-11.4)$ & $3.9(2.1-5.8)$ & 0.037 \\
\hline Gender, males, $n(\%)$ & $28(64)$ & $22(63)$ & $6(67)$ & 1.000 \\
\hline GCS $^{\mathrm{b}} \leq 8$ on admission, $n(\%)$ & $23(52)$ & $14(40)$ & $9(100)$ & 0.002 \\
\hline Presence of polytrauma, $n(\%)$ & $21(48)$ & $15(43)$ & $6(67)$ & 0.202 \\
\hline $\begin{array}{l}\text { Initial glucose, } \mathrm{mg} / \mathrm{dL} \text {, median } \\
\left(\mathrm{IQR}^{\mathrm{a}}\right)\end{array}$ & $180(131-257)$ & $153(131-234)$ & $245(212-369)$ & 0.116 \\
\hline $\begin{array}{l}\text { Initial glucose }>200 \mathrm{mg} / \mathrm{dL}, n \\
(\%)\end{array}$ & $19(43)$ & $12(34)$ & $7(78)$ & 0.027 \\
\hline $\begin{array}{l}\text { Pediatric trauma score, } \\
\text { median }\left(\mathrm{IQR}^{\mathrm{a}}\right)\end{array}$ & $4(3-6)$ & $4(4-7)$ & $1(0-3)$ & 0.001 \\
\hline Mechanism of injury, $n(\%)$ & & & & 0.048 \\
\hline Road traffic accident & $22(50)$ & $18(51)$ & $4(44)$ & \\
\hline Fall & $15(34)$ & $14(40)$ & $1(11)$ & \\
\hline Nonaccidental injury & $3(7)$ & $1(3)$ & $2(22)$ & \\
\hline Others & $4(9)$ & $2(6)$ & $2(22)$ & \\
\hline $\begin{array}{l}\text { Number requiring } \\
\text { neurosurgery, } n(\%)\end{array}$ & $31(71)$ & $26(74)$ & $5(56)$ & 0.272 \\
\hline
\end{tabular}

${ }^{\mathrm{a}} \mathrm{IQR}$ : interquartile range; ${ }^{\mathrm{b}} \mathrm{GCS}$ : Glasgow Coma Score.

values for 23 patients. On the first day after admission, the median of the highest ICP was $33 \mathrm{mmHg}$ (IQR 24-45). The highest and lowest CPP values were $93 \mathrm{mmHg}$ (IQR 86-105) and $40 \mathrm{mmHg}$ (IQR 20-48), respectively.

The median glucose in ED was $180.0 \mathrm{mg} / \mathrm{dL}\{10 \mathrm{mmol} / \mathrm{L}\}$ (IQR $131.4-257.4 \mathrm{mg} / \mathrm{dL} \quad\{7.3-14.3 \mathrm{mmol} / \mathrm{L}\}$ ). Two patients died in the ED. Both patients arrived with a GCS of 3 and had hypoglycemia on arrival $(45 \mathrm{mg} / \mathrm{dL}\{2.5 \mathrm{mmol} / \mathrm{L}\}$ and $18 \mathrm{mg} / \mathrm{dL}\{1 \mathrm{mmol} / \mathrm{L}\})$. Among the 42 patients who survived to admission, only five patients (11.9\%) received insulin infusion at 0-24 hours of admission, and four of these $(9.5 \%)$ continued to receive insulin infusion at $24-48$ hours of hospitalization. Fourteen of our patients $(31.8 \%)$ received inotropes. These consisted of dopamine, adrenaline, and noradrenaline, in varying combinations. The other 7 deaths occurred between the 3rd and 10th day of stay in the PICU. The separation of glucose levels between survivors and nonsurvivors was most marked at about 24 hours after arrival in the ED (Figure 2). Only 27 patients $(61.4 \%)$ had documented lactate levels (in the first 24 hours after arrival) because blood lactate was instituted only after the starting date of this retrospective study. The median peak level of lactate in the first 24 hours among these 27 patients was $2.6 \mathrm{mmol} / \mathrm{L}$ (IQR $1.7-4.8 \mathrm{mmol} / \mathrm{L}$ ).

Univariate analysis showed that age, GCS on presentation, presence of hyperglycemia, PTS (pediatric trauma score), and mechanism of injury were significantly associated with death (Table 1). There was a significant difference for 


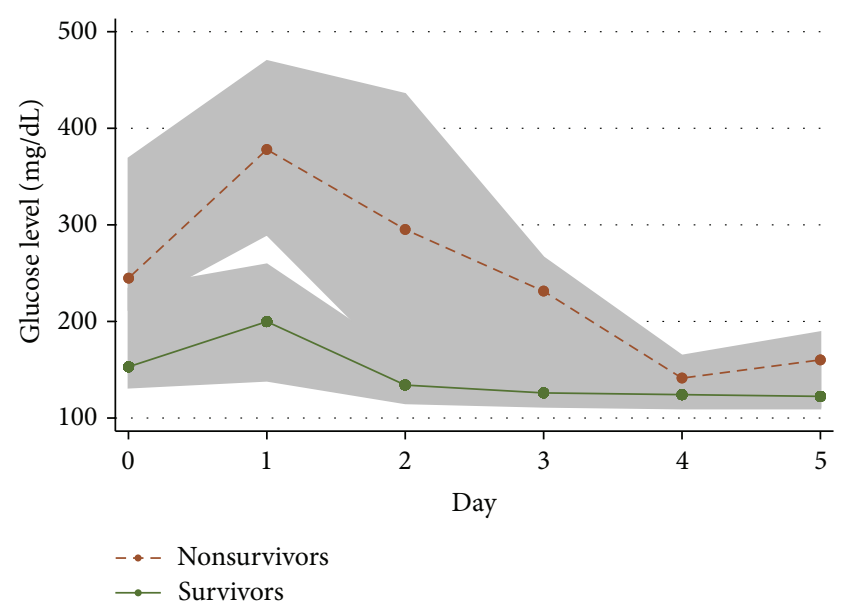

FIGURE 2: Glucose levels for survivors versus nonsurvivors over time. The points signify the median glucose levels and the shaded area signifies the interquartile range.

death, 14 PICU-free and 14 ventilation-free days between those with hyperglycemia and those with normoglycemia at the ED (Table 2). Excluding the two patients that died in the ED (both had hypoglycemia), seven out of the 19 (36.8\%) patients with initial hyperglycemia died, but no death was observed among the remaining 23 patients with normoglycemia $(p=0.019)$. Using a cutoff glucose of $150 \mathrm{mg} / \mathrm{dL}$ $(8.3 \mathrm{mmol} / \mathrm{L})$, hyperglycemia remained statistically significant for prolonged duration of mechanical ventilation and PICU stay (Table 2). Persistent hyperglycemia up to 48 and 72 hours was also significantly associated with increased risk of death $(83.3 \%$ in hyperglycemia group versus $5.6 \%$ in normoglycemia group at 48 hours, and $80 \%$ versus $5.6 \%$ at 72 hours, resp., $p<0.001$ ).

We went on to perform a stratified analysis of patients with GCS $\leq 8$. The effect of hyperglycemia on the above clinical outcomes was not significant (Table 3 ) at both cutoff values of $200 \mathrm{mg} / \mathrm{dL}(11.1 \mathrm{mmol} / \mathrm{L})$ and $150 \mathrm{mg} / \mathrm{dL}(8.3 \mathrm{mmol} / \mathrm{L})$.

There were three cases of nonaccidental injury (NAI) in our group. The first two patients who were finally diagnosed with subdural hemorrhage and died in hospital were both 3 years old. The third patient was a 1-year-old boy who presented with sudden onset of drowsiness and decreased movement, diagnosed with a right frontoparietal subdural hemorrhage. This child was discharged with recurrent focal seizures and required physiotherapy on follow-up. The first two patients had hyperglycemia on presentation as well as persistent hyperglycemia up to 48 hours.

On following up the patients in their course of PICU stay, 9 patients $(20.4 \%)$ had febrile illness, associated with bacteriological confirmation or clinical signs of sepsis; most of these were secondary to pneumonias or urinary tract infections.

\section{Discussion}

Our study among pediatric TBI patients showed that admission hyperglycemia has a significant association with poor clinical outcomes of death, duration of mechanical ventilation, and PICU LOS. However, stratified analysis of patients with GCS $\leq 8$ did not demonstrate an association between hyperglycemia and these clinical outcomes.

Hyperglycemia (both peak glucose and persistent hyperglycemia) has been shown to be an independent predictor for mortality among ill children in the PICU [21]. There are multifactorial causes of hyperglycemia consistent with the pathophysiological stress response after injury. The release of catecholamine and cortisol, together with glucose intolerance, has been documented in patients with head injury [2224]. Other studies have demonstrated that hyperglycemia worsens the impact of ischemia and hypoxia, leading to worse outcomes $[25,26]$. In addition, glucose metabolism changes significantly after TBI, as evident by the presence of mitochondrial dysfunction and increased cerebral utilization of glucose [27-29].

Serum glucose has previously been reported to be a prognostic factor in severe TBI (Table 4). In particular, high admission glucose $(\geq 200 \mathrm{mg} / \mathrm{dL}\{11.1 \mathrm{mmol} / \mathrm{L}\})$ has been demonstrated to be associated with poor outcomes, in both adults and children [4-12]. A proposed scale to be applied during the first hours after hospital admission in children with severe TBI included glucose as an independent predictor for death [3]. Our study findings were consistent with the current literature showing that the presence of hyperglycemia is associated with poor outcomes. In addition to increased mortality and poorer neurological outcomes, our study demonstrated that head-injured children with hyperglycemia also tend to have longer periods of mechanical ventilation and PICU stay. However, when we accounted for severity of injury using a stratified analysis, this effect was not significant. This lack of statistical association could be attributed to the small numbers in our study. We were not able to perform a multivariate analysis on the above predictors due to the small population size.

Randomized controlled trials in critically ill pediatric populations (not limited to TBI) have focused on the effect of tight glycemic control. One randomized controlled trial of critically ill children showed an improvement in inflammatory markers and reduced length of ICU stay in patients with tight glycemic control but also an increased risk of hypoglycemia [30]. However, a recent randomized trial among children admitted to the PICU showed no significant difference in the number of days alive and free from mechanical ventilation at 30 days after randomization, with the incidence of hypoglycemia being higher in the tight glucose control group compared to that with conventional glucose control [31]. Both of these studies did not describe in detail the subgroup of children with TBI and their corresponding severity. A study looking specifically at TBI patients would be able to better answer the question of whether glucose control may modify outcomes in pediatric TBI. Besides the peak and duration of hyperglycemia, glucose variability has also been shown to increase the risk of mortality, and any intervention should address this variability as well [32].

Focusing on other possible prognostic factors following pediatric TBI, we also found that the median PTS was significantly associated with mortality (Table 1). A previous 
TABLE 2: Presenting glucose as a predictor for clinical outcomes in patients with GCS $\leq 13$.

\begin{tabular}{|c|c|c|c|}
\hline $\begin{array}{l}\text { Hyperglycemia defined as } \\
\text { glucose }>200 \mathrm{mg} / \mathrm{dL} \\
(11.1 \mathrm{mmol} / \mathrm{L})\end{array}$ & $\begin{array}{c}\mathrm{ED}^{\mathrm{a}} \\
\text { normoglycemia } \\
(n=25)\end{array}$ & $\begin{array}{c}\mathrm{ED}^{\mathrm{a}} \\
\text { hyperglycemia } \\
(n=19)\end{array}$ & $p$ values \\
\hline Death, $n(\%)$ & $2(8)$ & $7(37)$ & 0.019 \\
\hline $\begin{array}{l}28 \text { hospital-free days, median } \\
\left(\mathrm{IQR}^{\mathrm{b}}\right)\end{array}$ & $21(6-23)$ & $11(0-20)$ & 0.222 \\
\hline $\begin{array}{l}14 \text { pediatric intensive care } \\
\text { unit-free days, median }\left(\mathrm{IQR}^{\mathrm{b}}\right)\end{array}$ & $11(7-12)$ & $6(3-10)$ & 0.006 \\
\hline $\begin{array}{l}14 \text { ventilation-free days, median } \\
\left(\mathrm{IQR}^{\mathrm{b}}\right)\end{array}$ & $12(8-13)$ & $8(4-10)$ & 0.008 \\
\hline $\begin{array}{l}\text { Hyperglycemia defined as } \\
\text { glucose }>150 \mathrm{mg} / \mathrm{dL} \\
(8.3 \mathrm{mmol} / \mathrm{L})\end{array}$ & $\begin{array}{c}\mathrm{ED}^{\mathrm{a}} \\
\text { normoglycemia } \\
(n=19)\end{array}$ & $\begin{array}{c}\mathrm{ED}^{\mathrm{a}} \\
\text { hyperglycemia } \\
(n=25)\end{array}$ & $p$ values \\
\hline Death, $n(\%)$ & $2(11)$ & $7(28)$ & 0.155 \\
\hline $\begin{array}{l}28 \text { hospital-free days, median } \\
\left(\mathrm{IQR}^{\mathrm{b}}\right)\end{array}$ & $21(7-23)$ & $18(0-23)$ & 0.273 \\
\hline $\begin{array}{l}14 \text { pediatric intensive care } \\
\text { unit-free days, median }\left(\mathrm{IQR}^{\mathrm{b}}\right)\end{array}$ & $11(7-12)$ & $6(3-10)$ & 0.032 \\
\hline $\begin{array}{l}14 \text { ventilation-free days, median } \\
\left(\mathrm{IQR}^{\mathrm{b}}\right)\end{array}$ & $12(8-13)$ & $8(4-11)$ & 0.021 \\
\hline
\end{tabular}

${ }^{\mathrm{a} E D:}$ emergency department; ${ }^{\mathrm{b}} \mathrm{IQR}$ : interquartile range.

TABLE 3: Presenting glucose as a predictor for clinical outcomes in patients with GCS $\leq 8(n=28)$.

\begin{tabular}{|c|c|c|c|}
\hline $\begin{array}{l}\text { Hyperglycemia defined as } \\
\text { glucose }>200 \mathrm{mg} / \mathrm{dL}(11.1 \mathrm{mmol} / \mathrm{L})\end{array}$ & $\begin{array}{c}\mathrm{ED}^{\mathrm{a}} \\
\text { normoglycemia } \\
(n=13)\end{array}$ & $\begin{array}{c}\mathrm{ED}^{\mathrm{a}} \\
\text { hyperglycemia } \\
(n=15)\end{array}$ & $p$ values \\
\hline Death, $n(\%)$ & $2(15)$ & $7(47)$ & 0.077 \\
\hline 28 hospital-free days, median $\left(\mathrm{IQR}^{\mathrm{b}}\right)$ & $5(0-23)$ & $10(0-23)$ & 0.587 \\
\hline $\begin{array}{l}14 \text { pediatric intensive care unit-free days, } \\
\text { median }\left(\mathrm{IQR}^{\mathrm{b}}\right)\end{array}$ & $7(0-12)$ & $5(2-10)$ & 0.815 \\
\hline 14 ventilation-free days, median $\left(\mathrm{IQR}^{\mathrm{b}}\right)$ & $8(0-13)$ & $7(2-10)$ & 0.889 \\
\hline $\begin{array}{l}\text { Hyperglycemia defined as } \\
\text { glucose }>150 \mathrm{mg} / \mathrm{dL}(8.3 \mathrm{mmol} / \mathrm{L})\end{array}$ & $\begin{array}{c}\mathrm{ED}^{\mathrm{a}} \\
\text { normoglycemia } \\
(n=9)\end{array}$ & $\begin{array}{c}\mathrm{ED}^{\mathrm{a}} \\
\text { hyperglycemia } \\
(n=19)\end{array}$ & $p$ values \\
\hline Death, $n(\%)$ & $2(22)$ & $7(37)$ & 0.439 \\
\hline 28 hospital-free days, median $\left(\mathrm{IQR}^{\mathrm{b}}\right)$ & $5(0-7)$ & $10(0-23)$ & 0.668 \\
\hline $\begin{array}{l}14 \text { pediatric intensive care unit-free days, } \\
\text { median }\left(\mathrm{IQR}^{\mathrm{b}}\right)\end{array}$ & $7(0-8)$ & $5(0-10)$ & 0.960 \\
\hline 14 ventilation-free days, median (IQR $\left.{ }^{\mathrm{b}}\right)$ & $8(0-9)$ & $7(2-11)$ & 0.901 \\
\hline
\end{tabular}

${ }^{\mathrm{a}} \mathrm{ED}$ : emergency department; ${ }^{\mathrm{b}} \mathrm{IQR}$ : interquartile range.

report of 180 patients [33] demonstrated that patients with serious concomitant injuries had fewer days off mechanical ventilation and longer hospital stay, although it did not significantly predict for mortality. In the above study, patients with serious concomitant injuries were most likely involved in motor vehicle accidents and had more severe TBI [33]. In another study of 100 adults with TBI, high grade concomitant injuries were associated with functional disability 18 months after the injury [34].

We looked specifically at our patients with NAI because this is a special subset in the vulnerable pediatric population.
It has been previously reported that GCS and PTS both predict for mortality among children with NAI [35]. The glycemic response in these children may also differ from other types of TBI, evident from a previous report that inflicted TBI patients displayed a $14 \%$ reduction in peak stimulated cortisol compared with accidental TBI patients [36]. In another study focusing on inflicted traumatic brain injury among 35 children [37], initial hyperglycemia was found to be significantly associated with a poorer Glasgow Outcome Scale score. However, when controlled for age at injury and time since injury on multivariate analysis, the 


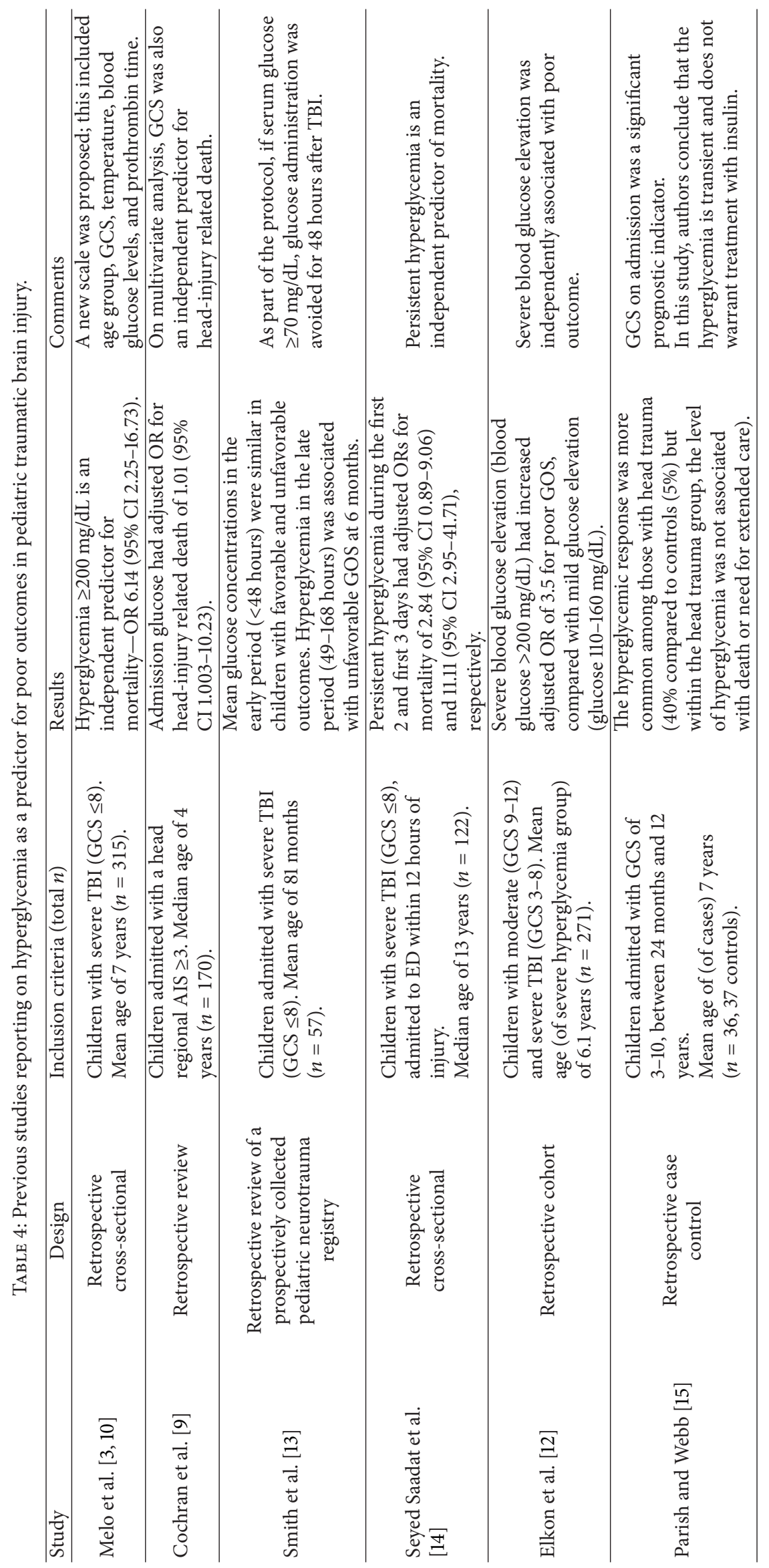


association was not significant. Two out of our three patients with NAI had hyperglycemia on presentation that persisted for up to 48 hours.

We recognize the following limitations in our study: (1) Small numbers: this was due to a low prevalence of moderate and severe TBI in our population. We look forward to accrual of more data with a prospective surveillance registry. (2) Over the period in which we utilized the data, there may be unmeasured differences in clinical management with regard to ventilator management and intracranial pressure control strategies, both of which may potentially affect the clinical outcomes of interest in our study. These changes include moving from the use of mannitol to 3\% hypertonic saline as the preferred hyperosmolar agent and maintaining normothermia instead of instituting hypothermia for patients with TBI. Other aspects of first and second tier management have not otherwise changed significantly. (3) There was no uniform protocol guiding the use of insulin for persistent hyperglycemia throughout this study period.

\section{Conclusion}

Hyperglycemia, in children with moderate and severe TBI, is associated with mortality, prolonged duration of mechanical ventilation, and longer duration of PICU stay. Our findings build on the current evidence that in-hospital outcomes are adversely associated with hyperglycemia. Our findings are part of an ongoing study to derive prognostic factors for pediatric TBI in our center. To address the question of whether glucose control impacts clinical outcomes in children with TBI, we propose that future research on glucose homeostasis in critically ill children focuses specifically on children with moderate and severe TBI.

\section{Conflict of Interests}

The authors declare that there is no conflict of interests regarding the publication of this paper.

\section{Acknowledgments}

The authors would like to thank Dr. Misa Noda, Ms. Jasmine Feng, and Ms. Lau Yew Ping for their assistance in this study. There was no financial support used for the study. This work was performed at KK Women's and Children's Hospital, Singapore.

\section{References}

[1] W. Rutland-Brown, J. A. Langlois, K. E. Thomas, and Y. L. Xi, "Incidence of traumatic brain injury in the United States, 2003," Journal of Head Trauma Rehabilitation, vol. 21, no. 6, pp. 544548, 2006.

[2] Injury Prevention and Control: Traumatic brain injury, 2014, http://www.cdc.gov/ncipc/tbi/tbi_report/index.htm.

[3] J. R. Tude Melo, F. di Rocco, S. Blanot et al., "Mortality in children with severe head trauma: predictive factors and proposal for a new predictive scale," Neurosurgery, vol. 67, no. 6, pp. 1542-1547, 2010.
[4] B. Young, L. Ott, R. Dempsey, D. Haack, and P. Tibbs, "Relationship between admission hyperglycemia and neurologic outcome of severely brain-injured patients," Annals of Surgery, vol. 210, no. 4, pp. 466-473, 1989.

[5] A. Rovlias and S. Kotsou, "The influence of hyperglycemia on neurological outcome in patients with severe head injury," Neurosurgery, vol. 46, no. 2, pp. 335-343, 2000.

[6] E. Jeremitsky, L. A. Omert, C. M. Dunham, J. Wilberger, and A. Rodriguez, "The impact of hyperglycemia on patients with severe brain injury," Journal of Trauma, vol. 58, no. 1, pp. 47-50, 2005.

[7] F. Yuan, J. Ding, H. Chen et al., "Predicting outcomes after traumatic brain injury: the development and validation of prognostic models based on admission characteristics," Journal of Trauma and Acute Care Surgery, vol. 73, no. 1, pp. 137-145, 2012.

[8] A. Chiaretti, M. Piastra, S. Pulitanò et al., "Prognostic factors and outcome of children with severe head injury: an 8-year experience," Child's Nervous System, vol. 18, no. 3-4, pp. 129-136, 2002.

[9] A. Cochran, E. R. Scaife, K. W. Hansen, and E. C. Downey, "Hyperglycemia and outcomes from pediatric traumatic brain injury," Journal of Trauma-Injury, Infection and Critical Care, vol. 55, no. 6, pp. 1035-1038, 2003.

[10] J. R. T. Melo, F. Di Rocco, S. Blanot et al., "Acute hyperglycemia is a reliable outcome predictor in children with severe traumatic brain injury," Acta Neurochirurgica, vol. 152, no. 9, pp. 1559-1565, 2010.

[11] N. Aşilioğlu, F. Turna, and M. Ş. Paksu, "Admission hyperglycemia is a reliable outcome predictor in children with severe traumatic brain injury," Jornal de Pediatria, vol. 87, no. 4, pp. 325-328, 2011.

[12] B. Elkon, J. R. Cambrin, E. Hirshberg, and S. L. Bratton, "Hyperglycemia: an independent risk factor for poor outcome in children with traumatic brain injury," Pediatric Critical Care Medicine, vol. 15, no. 7, pp. 623-631, 2014.

[13] R. L. Smith, J. C. Lin, P. D. Adelson et al., "Relationship between hyperglycemia and outcome in children with severe traumatic brain injury," Pediatric Critical Care Medicine, vol. 13, no. 1, pp. 85-91, 2012.

[14] S. M. Seyed Saadat, E. Bidabadi, S. N. Seyed Saadat, M. Mashouf, F. Salamat, and S. Yousefzadeh, "Association of persistent hyperglycemia with outcome of severe traumatic brain injury in pediatric population," Child's Nervous System, vol. 28, no. 10, pp. 1773-1777, 2012.

[15] R. A. Parish and K. S. Webb, "Hyperglycemia is not a poor prognostic sign in head-injured children," Journal of Trauma, vol. 28, no. 4, pp. 517-519, 1988.

[16] C. H. Kan, M. Saffari, and T. H. Khoo, "Prognostic factors of severe traumatic brain injury outcome in children aged 216 years at a major Neurosurgical Referral Centre," Malaysian Journal of Medical Sciences, vol. 16, no. 4, pp. 25-33, 2009.

[17] J. S. Hutchison, R. E. Ward, J. Lacroix et al., "Hypothermia therapy after traumatic brain injury in children," The New England Journal of Medicine, vol. 358, no. 23, pp. 2447-2456, 2008.

[18] P. D. Adelson, S. R. Wisniewski, J. Beca et al., "Comparison of hypothermia and normothermia after severe traumatic brain injury in children (Cool Kids): a phase 3, randomised controlled trial," The Lancet Neurology, vol. 12, no. 6, pp. 546-553, 2013.

[19] J. J. Tepas III, D. L. Mollitt, J. L. Talbert, and M. Bryant, “The pediatric trauma score as a predictor of injury severity in the 
injured child," Journal of Pediatric Surgery, vol. 22, no. 1, pp. 14$18,1987$.

[20] J. J. Tepas III, M. L. Ramenofsky, D. L. Mollitt, B. M. Gans, and C. DiScala, "The Pediatric Trauma Score as a predictor of injury severity: an objective assessment," Journal of Trauma, vol. 28, no. 4, pp. 425-429, 1988.

[21] V. Srinivasan, P. C. Spinella, H. R. Drott, C. L. Roth, M. A. Helfaer, and V. Nadkarni, "Association of timing, duration, and intensity of hyperglycemia with intensive care unit mortality in critically ill children," Pediatric Critical Care Medicine, vol. 5, no. 4, pp. 329-336, 2004.

[22] T. Pentelényi, L. Kammerer, F. Péter et al., "Prognostic significance of the changes in the carbohydrate metabolism in severe head injury," in Proceedings of the 6th European Congress of Neurosurgery, vol. 28 of Acta Neurochirurgica, pp. 103-107, Springer, Vienna, Austria, 1979.

[23] T. Pentelenyi, L. Kammerer, M. Stutzel, and I. Balazsi, "Alterations of the basal serum insulin and blood glucose in braininjured patients," Injury, vol. 10, no. 3, pp. 201-208, 1979.

[24] L. R. King, H. C. Knowles Jr., R. L. McLaurin, and H. P. Lewis, "Glucose tolerance and plasma insulin in cranial trauma," Annals of Surgery, vol. 173, no. 3, pp. 337-343, 1971.

[25] W. T. Longstreth Jr. and T. S. Inui, "High blood glucose level on hospital admission and poor neurological recovery after cardiac arrest," Annals of Neurology, vol. 15, no. 1, pp. 59-63, 1984.

[26] W. A. Pulsinelli, D. E. Levy, B. Sigsbee, P. Scherer, and F. Plum, "Increased damage after ischemic stroke in patients with hyperglycemia with or without established diabetes mellitus," The American Journal of Medicine, vol. 74, no. 4, pp. 540-544, 1983.

[27] B. H. Verweij, J. P. Muizelaar, F. C. Vinas, P. L. Peterson, Y. Xiong, and C. P. Lee, "Impaired cerebral mitochondrial function after traumatic brain injury in humans," Journal of Neurosurgery, vol. 93, no. 5, pp. 815-820, 2000.

[28] M. Bergsneider, D. A. Hovda, E. Shalmon et al., "Cerebral hyperglycolysis following severe traumatic brain injury in humans: a positron emission tomography study," Journal of Neurosurgery, vol. 86, no. 2, pp. 241-251, 1997.

[29] D. A. Hovda, S. M. Lee, M. L. Smith et al., "The neurochemical and metabolic cascade following brain injury: moving from animal models to man," Journal of Neurotrauma, vol. 12, no. 5, pp. 903-906, 1995.

[30] D. Vlasselaers, I. Milants, L. Desmet et al., "Intensive insulin therapy for patients in paediatric intensive care: a prospective, randomised controlled study," The Lancet, vol. 373, no. 9663, pp. 547-556, 2009.

[31] D. Macrae, R. Grieve, E. Allen et al., "A randomized trial of hyperglycemic control in pediatric intensive care," The New England Journal of Medicine, vol. 370, no. 2, pp. 107-118, 2014.

[32] A. J. Rake, V. Srinivasan, V. Nadkarni, R. Kaptan, and C. J. L. Newth, "Glucose variability and survival in critically ill children: allostasis or harm?" Pediatric Critical Care Medicine, vol. 11, no. 6, pp. 707-774, 2010.

[33] T. C. Stewart, I. M. Alharfi, and D. D. Fraser, "The role of serious concomitant injuries in the treatment and outcome of pediatric severe traumatic brain injury," Journal of Trauma and Acute Care Surgery, vol. 75, no. 5, pp. 836-842, 2013.

[34] B. K. Leong, M. Mazlan, R. B. A. Rahim, and D. Ganesan, "Concomitant injuries and its influence on functional outcome after traumatic brain injury," Disability and Rehabilitation, vol. 35, no. 18, pp. 1546-1551, 2013.
[35] D. Scavarda, C. Gabaudan, F. Ughetto et al., "Initial predictive factors of outcome in severe non-accidental head trauma in children," Child's Nervous System, vol. 26, no. 11, pp. 1555-1561, 2010.

[36] N. L. Heather, J. G. B. Derraik, C. Brennan et al., "Cortisol response to synacthen stimulation is attenuated following abusive head trauma," Clinical Endocrinology, vol. 77, no. 3, pp. 357-362, 2012.

[37] T. Rhine, S. L. Wade, K. L. Makoroff, A. Cassedy, and L. J. Michaud, "Clinical predictors of outcome following inflicted traumatic brain injury in children," The Journal of Trauma and Acute Care Surgery, vol. 73, no. 4, pp. S248-S253, 2012. 


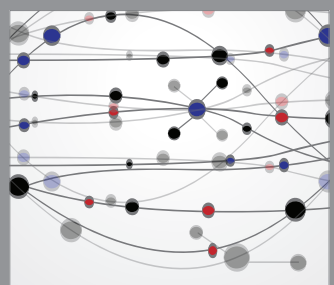

The Scientific World Journal
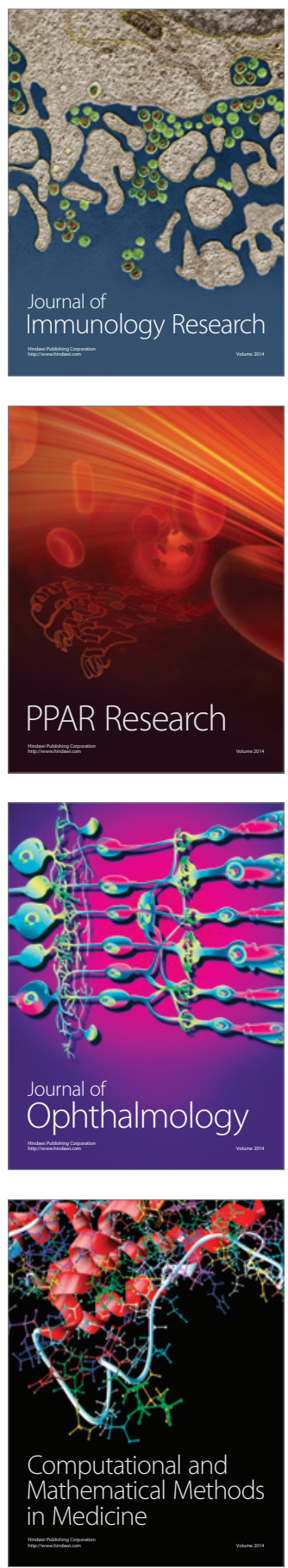

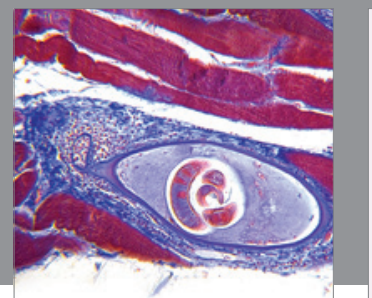

Gastroenterology

Research and Practice
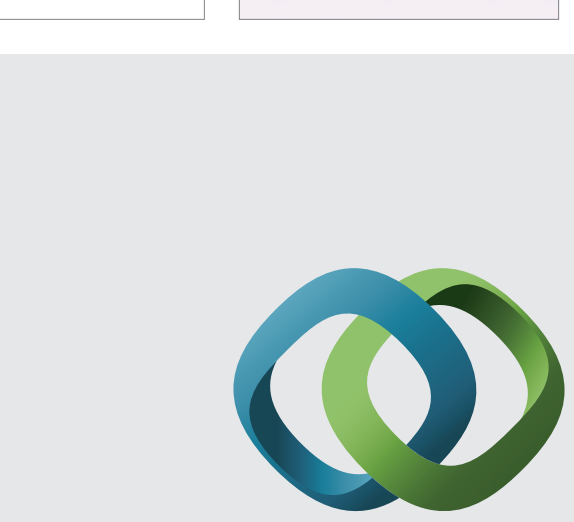

\section{Hindawi}

Submit your manuscripts at

http://www.hindawi.com
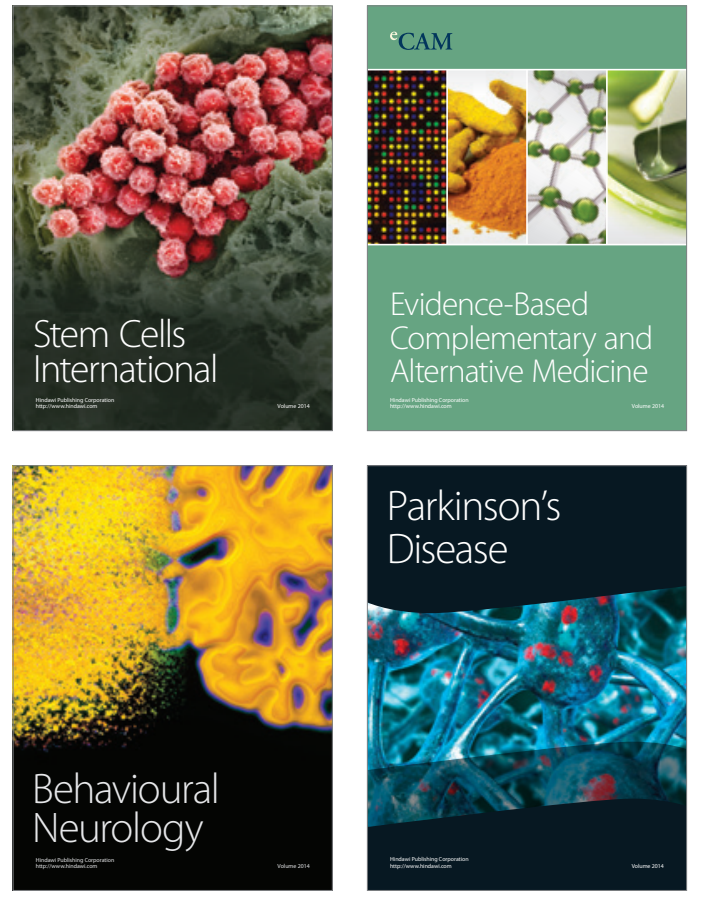
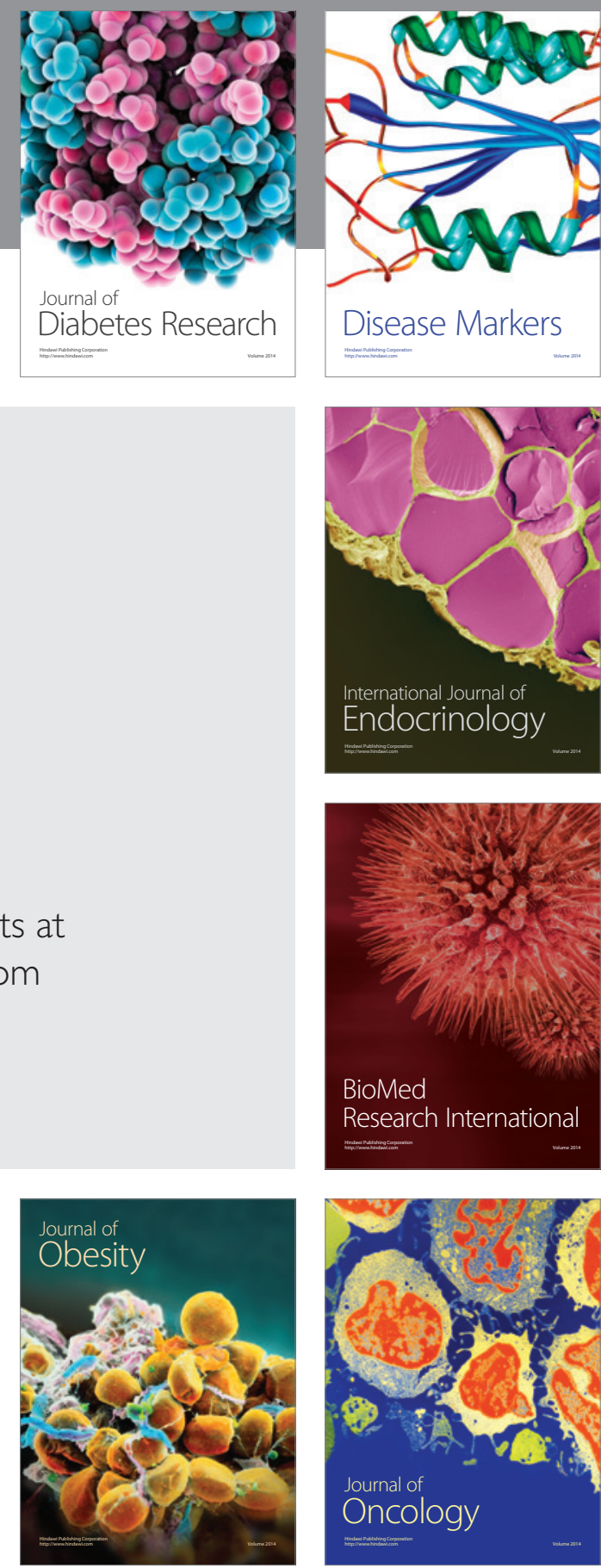

Disease Markers
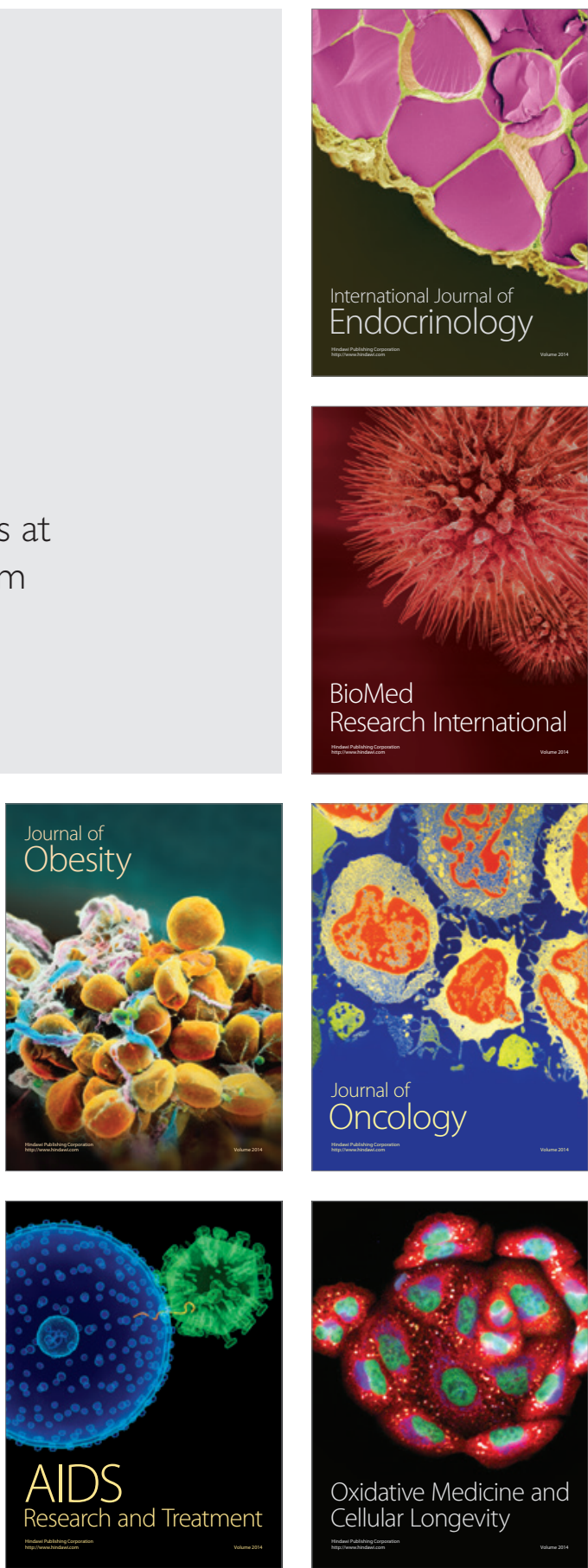